\title{
Research on the prediction of financial expenditure for the assistance and support of the extremely poor in China
}

\author{
Jin Zhang \\ Central University of Finance and Economics, \\ School of Insurance
}

\begin{abstract}
Extremely poor people are the most difficult part of the poor in China, and they are also an important part of China's fight against poverty. The policy of assisting and supporting the extremely poor people has played an important role in ensuring the survival and living needs of the extremely poor people in urban and rural areas, and realizing the goal of sharing the development results for the whole people. Since 2015, the assistance and support system for the extremely poor has been disbursed separately, the financial expenditure has increased year by year, from 18.297 billion yuan to $\mathbf{2 5 . 9 3 0}$ billion yuan, and the annual financial account expenditure exceeds the budgeted expenditure every year. Therefore, it is urgent to make accurate and reasonable expectation on the financial expenditure of the relief of the extremely poor. Based on the analysis of financial support for the assistance and support of the poorest people from 2008 to 2018, this paper uses the Holt index forecast method to predict the social assistance expenditure for the next five years, and concludes that future financial needs will improve the support and assistance of the special hardship.
\end{abstract}

Keywords: assistance and support for the extremely poor people, financial expenditure forecast, Holt index method

\section{QUESTIONS RAISED}

The state protects the right to Subsistence and development of all citizens in accordance with the law. Some people have lost their own labor force or lack the ability to act independently, thus falling into a survival dilemma and being in a disadvantaged position in society. Social assistance is an important way to guarantee the vulnerable groups to obtain the right to survival and development in accordance with the law (Lin, 2017). The state finance must bear the assistance and support work for the extremely poor.

China's assistance and support expenditure for the extremely poor was initially included in the urban minimum living security expenditure, which was divided into quantitative new subsidies and temporary service assistance. In 2014, the Interim Measures for Social Assistance, which issued by Order No. 649 of the State Council of China, announced that the integration of the original system of "three no staff" in cities ${ }^{1}$ and "Five Guarantees" in rural areas to form a assistance and support system for the extremely poor. The assistance and support for the extremely poor officially appears in the legal provisions of the state, realizing the separate expenditure in the financial account. The current assistance and support system for the extremely poor covers the elderly, disabled people in urban and rural areas, and the minors under the age of 16 who have no ability to work, no source of livelihood, no fixed support and support obligations or whose legal obligations have no ability to perform their obligations. The capital expenditure of the extremely poor people in urban and rural areas is borne by the state and local governments at different levels, mainly comes from the financial

\footnotetext{
${ }^{1}$ It means that the transient without proper work, lawful identification or permanent address in cities.
} 
and tax revenue. Since 2015, the financial expenditure for the assistance and support of the extremely poor has increased from 18.297 billion yuan to 25.930 billion yuan, with an average annual growth rate of $16.6 \%$. For a long time, the financial long-term budget planning for the relief of the extremely poor is relatively lacking, and according to the budget results of one year, the annual final accounts expenditure exceeds the budget expenditure, especially in the support of the extremely poor people in the city, the financial budget level is far less than the expenditure level of that year. Therefore, it is urgent to make an accurate and reasonable prediction on the financial expenditure for the assistance and support of the extremely poor.

\section{CURRENT SITUATION ANALYSIS}

Before the calculation of the financial expenditure for the assistance and support of the extremely poor, it is necessary to clarify the expenditure situation and the scale of the assistance for the extremely poor in the previous years. Because the time for the account to be separately disbursed is relatively short, it is necessary to conduct a comprehensive analysis in combination with the expenditure for the "three no staff" in the city and the expenditure for the "five guarantees" in the countryside. The following will make a specific analysis of the situation in the past 10 years.

\section{Financial expenditure for assistance and support of the extremely poor}

Before the promulgation of the Interim Measures for social assistance in 2014, the assistance and support for the rural extremely poor people existed in the form of five guarantees. According to the relevant provisions on the minimum living standard of urban residents issued in 1997, the urban extremely poor people were disbursed in the minimum living standard of urban residents, unable to calculate the specific data. Until the civil affairs statistics in 2012, the expenditure data of the urban three no people were only single publicity alone. In 2014, the urban "three no staff" relief and rural "Five Guarantees" support personnel were formally merged into the extremely poor for assistance and support, which were separately disbursed in the financial expenditure. According to the 2009-2018 civil affairs statistical yearbook and the 2008-2018 social service development statistical bulletin, the financial expenditure for the assistance and support of the extremely poor across the country is sorted out, and the results are shown in the table below.

Table 1 Assistance expenditure for China 's extremely poor people and its share in China's finance expenditure

Unit: 100 million yuan

\begin{tabular}{ccccc}
\hline Year & Urban poverty & Rural poverty & $\begin{array}{c}\text { Total expenditure in } \\
\text { extreme poverty }\end{array}$ & $\begin{array}{c}\text { Proportion of } \\
\text { financial expenditure }\end{array}$ \\
\hline 2008 & - & 73.67 & 73.67 & $0.12 \%$ \\
2009 & - & 88.03 & 88.03 & $0.12 \%$ \\
2010 & - & 87.51 & 87.51 & $0.10 \%$ \\
2011 & - & 111.86 & 111.86 & $0.10 \%$ \\
2012 & 4.82 & 124.06 & 128.88 & $0.10 \%$ \\
2013 & 4.15 & 154.03 & 158.18 & $0.11 \%$ \\
2014 & 5.12 & 164.03 & 169.15 & $0.11 \%$ \\
2015 & 7.46 & 175.51 & 182.97 & $0.10 \%$ \\
2016 & 15.05 & 212.61 & 227.66 & $0.12 \%$ \\
2017 & 27.46 & 231.84 & 259.3 & $0.13 \%$ \\
2018 & 29.5 & 306.9 & 336.4 & $0.15 \%$ \\
\hline
\end{tabular}

Data source: According to civil affairs statistical yearbook and social service statistical bulletin 
Fig.1 2008-2018 Financial expenditure for assistance and support for the extremely poor in China

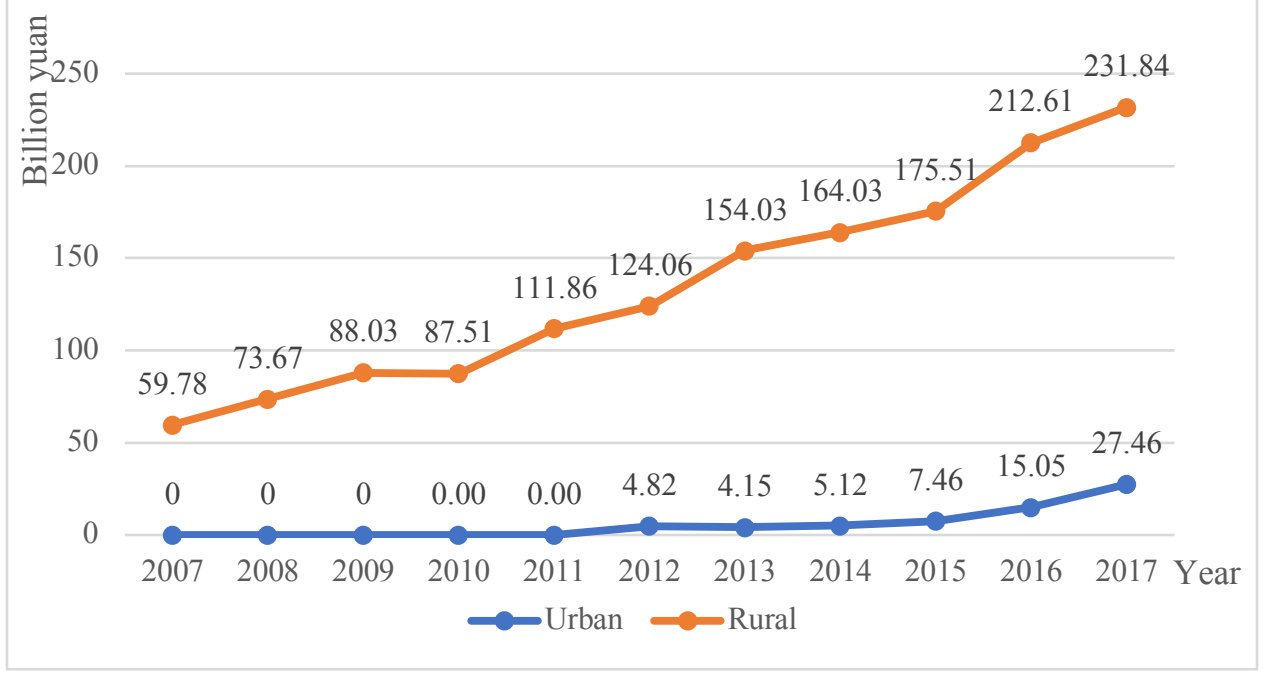

Table 2 Financial expenditure for assistance and support for the poor people in different provinces of China in 2017 Unit: 10,000 yuan

\begin{tabular}{cccc}
\hline Province & $\begin{array}{c}\text { Expenditure for urban } \\
\text { extremely poor }\end{array}$ & $\begin{array}{c}\text { Expenditure for rural } \\
\text { extremely poor }\end{array}$ & $\begin{array}{c}\text { Total expenditure of } \\
\text { the extremely poor }\end{array}$ \\
\hline Beijing & 2598.0 & 7801.3 & 10399.3 \\
Tianjin & 2742.6 & 19752.3 & 22494.9 \\
Hebei & 1225.2 & 126872.6 & 128097.8 \\
Shanxi & 389.1 & 67692.9 & 68082.0 \\
Inner Mongolia & 18409.5 & 56805.4 & 75214.9 \\
Liaoning & 3413.4 & 59485.0 & 62898.4 \\
Jilin & 1742.1 & 22800.1 & 24542.2 \\
Heilongjiang & 11046.9 & 65688.7 & 76735.6 \\
Shanghai & 643.7 & 3512.6 & 4156.3 \\
Jiangsu & 5177.2 & 144256.8 & 149434.0 \\
Zhejiang & 3411.6 & 26788.2 & 30199.8 \\
Anhui & 405.9 & 198144.3 & 198550.2 \\
Fujian & 3463.2 & 58750.4 & 62213.6 \\
Jiangxi & 8345.3 & 104203.6 & 112548.9 \\
Shandong & 1863.2 & 110861.4 & 112724.6 \\
Henan & 1833.0 & 208117.6 & 209950.6 \\
Hubei & 8985.7 & 230399.8 & 239385.5 \\
Hunan & 17653.7 & 205262.3 & 222916.0 \\
Guangdong & 6212.7 & 208403.6 & 214616.3 \\
Guangxi & 7931.2 & 114989.5 & 122920.7 \\
Hainan & 1738.8 & 19065.5 & 20804.3 \\
Chongqing & 51784.0 & 97517.2 & 149301.2 \\
Sichuan & 21349.1 & 199683.9 & 221033.0 \\
Guizhou & 2896.2 & 53181.8 & 56078.0 \\
Yunnan & 11286.2 & 77113.7 & 88399.9 \\
Tibet & -12504.2 & 12504.2 \\
Shaanxi & 3098.8 & 12504.2 & 55620.2 \\
Gansu & 1528.5 & 97067.4 & 26653.4 \\
Qinghai & 4641.7 & 54091.7 & 19481.1 \\
Ningxia & 1265.0 & 22011.7 & \\
Xinjiang & 4613.3 & 14867.1 & \\
\hline & 1.9 & \\
\hline
\end{tabular}

Data source: According to civil affairs statistical yearbook 
It can be seen from Figure 1 that in the past 10 years, despite the continuous implementation of the targeted poverty alleviation policy, the state has gradually helped some urban and rural residents out of poverty. However, the extremely poor people are the most difficult to get rid of poverty, and they need to be supported by the national finance for a long time. With the improvement of the standard of support, the financial expenditure on the assistance and support of the extremely poor people is increasing year by year, especially in the support of the extremely poor people in rural areas. In 2018, the relevant financial expenditure has reached 33.640 billion yuan. From 2008 to 2018, the financial expenditure on the assistance and support of the extremely poor people in rural areas increased annually, the growth rate is as high as $16.78 \%$, far higher than the average GDP growth rate. The main reason for the increasing pressure of the State Finance on the assistance and support expenditure for the extremely poor is the aging population and the increasing per capita consumption expenditure. Under the double pressure, the number of the extremely poor is high. Secondly, it can be seen from Table 2 that due to the relatively extensive provisions of the state on the relief of the extremely poor, there are large differences in the formulation of standards in different regions, which ultimately leads to a large gap in the expenditure on the assistance and support of the extremely poor. In addition to the lack of data on urban minimum living security in Tibet, Shanxi Province has the lowest expenditure on urban relief for the extremely poor, which is only 3.891 million yuan; Chongqing has the highest expenditure on urban relief for the extremely poor, which is 518 million yuan. The gap between the two regions in terms of urban aid expenditure alone reached 514 million yuan. In terms of the assistance for the poor in rural areas, Shanghai, with a high degree of urbanization, only spent 35 million yuan, but in Henan, Hubei, Hunan, Guangdong and Qinghai provinces, the assistance for the poor in rural areas exceeded 2 billion yuan. In terms of total expenditure, the gap between Shanghai, which has the least expenditure, and Hubei Province, which has the most expenditure, is 2.352 billion yuan. Because of the difference of economic development level and rescue level, it is not easy for government finance to supervise regional rescue.

\section{Status of assistance for special hardship personnel}

Since the implementation of the five guarantees support system in rural areas, especially after the implementation of the Regulations on Five Guarantees Support in Rural Areas in 2006, statistics on the protection of rural people in need have been carried out separately in civil administration statistics. and in 2010, separate statistics were also performed in urban three no staff support system. From the statistical data, we can see that the scale of assistance and support for rural poor people has kept a steady increase before 2010, reaching a peak of 5.563 million in 2010. Since then, the scale of assistance for rural poor people has been decreasing year by year, and fell to 4.55 million in 2018. It shows that in recent years, China's poverty alleviation policy, especially after the implementation of precision poverty alleviation, has achieved remarkable results in poverty alleviation among rural poor people in China. It can be seen from the rescue of the urban poor that after the initial "three-none" rescue of the city to separate expenditures, especially after the implementation of the urban special hardship rescue and support policy in 2014, the rescue workers are still rising year by year. 
Table 3 Assistance scale for extremely poor people from 2008 to 2018

Unit: 10,000

\begin{tabular}{ccccc}
\hline \multirow{2}{*}{ Year } & \multirow{2}{*}{$\begin{array}{c}\text { Assistance number of } \\
\text { urban poor people }\end{array}$} & Total & $\begin{array}{c}\text { Centralized } \\
\text { support }\end{array}$ & $\begin{array}{c}\text { Scattered } \\
\text { support }\end{array}$ \\
\cline { 3 - 5 } 2007 & -- & 531.3 & 138 & 393.3 \\
2008 & - & 548.6 & 155.6 & 393 \\
2009 & -- & 553.4 & 171.8 & 381.6 \\
2010 & 14.7 & 556.3 & 177.4 & 378.9 \\
2011 & 19.3 & 551.0 & 184.5 & 366.5 \\
2012 & 9.9 & 545.6 & 185.3 & 360.3 \\
2013 & 8.6 & 537.2 & 183.5 & 353.8 \\
2014 & 7.6 & 529.1 & 174.3 & 354.8 \\
2015 & 6.8 & 516.7 & 162.3 & 354.4 \\
2016 & 9.1 & 496.9 & 139.7 & 357.2 \\
2017 & 25.4 & 466.9 & -- & -- \\
2018 & 27.7 & 455.0 & -- & - \\
\hline
\end{tabular}

Data resource: Sorted out according to civil affairs statistical yearbook and civil affairs statistical bulletin; the above statistical data do not include Hong Kong, Macao and Taiwan

Secondly, in order to improve the conditions for the support of the extremely poor, since 2006, the "Xia Guang Plan" to improve the construction of rural support service facilities has been implemented nationwide, and funds have been invested to support the construction, reconstruction and expansion of local support service institutions and improve the conditions of support service. According to the statistics, more than 30 thousand villages and towns across the country have basically realized that each town has built itself, or several towns have built together, a special support institution for the poor elderly, a special support institution for the poor children and a support institution for the severely disabled in each place. By the end of 2014, there were 3.93 million beds for the elderly and the disabled, 102.2 thousand beds for the children, and more than 260 thousand service personnel. At the same time, in order to promote the institutionalization and standardization of the management of the support service institutions, and constantly improve the level of the support service, the Ministry of Civil Affairs has successively issued regulations to establish the rating system of the rural five guarantee support institutions. Through these efforts, the basic life of the extremely poor in China is guaranteed. However, due to the limited funds and service ability of the support service institutions, and the lack of professional service nurses, the support service for the extremely poor is relatively weak, especially for the life care and nursing which has lost the ability of self-care. 
Table 4 Assistance scale of the extremely poor in each province in 2017

Unit: person, $\%$

\begin{tabular}{cccccccccc}
\hline Province & Urban & Pro. & Rural & Pro. & Province & Urban & Pro. & Rural & Pro. \\
\hline Beijing & 978 & 0.01 & 4503 & 0.15 & Hubei & 8610 & 0.02 & 245735 & 1.02 \\
Tianjin & 1711 & 0.01 & 11097 & 0.42 & Hunan & 13633 & 0.04 & 378704 & 1.22 \\
Hebei & 2365 & 0.01 & 231930 & 0.69 & Guangdong & 5944 & 0.01 & 226050 & 0.67 \\
Shanxi & 876 & 0.00 & 146500 & 0.93 & Guangxi & 4812 & 0.02 & 250418 & 1.01 \\
Inner Mongolia & 11855 & 0.08 & 83810 & 0.87 & Hainan & 911 & 0.02 & 26291 & 0.68 \\
Liaoning & 4062 & 0.01 & 130738 & 0.92 & Chongqing & 72120 & 0.37 & 111468 & 1.01 \\
Jilin & 2251 & 0.01 & 107727 & 0.91 & Sichuan & 49504 & 0.12 & 459085 & 1.12 \\
Heilongjiang & 8907 & 0.04 & 112630 & 0.73 & Guizhou & 4591 & 0.03 & 83793 & 0.43 \\
Shanghai & 747 & 0.00 & 2292 & 0.08 & Yunnan & 10579 & 0.05 & 138008 & 0.54 \\
Jiangsu & 8510 & 0.02 & 200186 & 0.80 & Tibet & -- & 0.00 & 14662 & 0.63 \\
Zhejiang & 3535 & 0.01 & 27764 & 0.15 & Shaanxi & 3014 & 0.01 & 119700 & 0.72 \\
Anhui & 905 & 0.00 & 397711 & 1.37 & Gansu & 3201 & 0.03 & 111163 & 0.79 \\
Fujian & 4340 & 0.02 & 67114 & 0.49 & Qinghai & 1659 & 0.05 & 20576 & 0.73 \\
Jiangxi & 9390 & 0.04 & 210870 & 1.01 & Ningxia & 677 & 0.02 & 9976 & 0.35 \\
Shandong & 2022 & 0.00 & 210461 & 0.53 & Xinjiang & 8237 & 0.07 & 39289 & 0.32 \\
Henan & 3747 & 0.01 & 488649 & 1.03 & & & & & \\
\hline
\end{tabular}

Data source: China Civil Affairs Statistical Yearbook 2018

In 2017, China's total number of people receiving assistance and support for the poorest people was 4.923 million. In that year, the total urban and rural population was 13.998 million, and the national population accounted for $0.35 \%$. From the perspective of urban and rural areas, due to the differences in urban and rural development levels, there is a large difference in the situation of urban and rural poverty relief assistance. In 2017, the proportion of the urban population enjoying special assistance and assistance in the poor was only $0.31 \%$; the rural population enjoying special poverty assistance and assistance in the total rural population accounted for $0.81 \%$. From the cross-sectional level of the country, there are some differences in the support levels of the poor people in the provinces. In terms of assistance and support for the urban poor people, Chongqing has the highest proportion of the urban population enjoying assistance and support for the poor people, reaching $0.37 \%$ of the total urban population. Except for the lack of data on the number of people who enjoy the assistance and support of the urban poor in Tibet, 9 provinces such as Anhui, Shandong, Shanghai and Shanxi, the proportion of urban people in special poverty being assisted is less than $0.01 \%$. Among them, Shanghai has the least number of urban residents in need of assistance and support, only 747. From the aspect of assistance and support for the extremely poor people in rural areas, the number of rural people enjoying assistance and support for the extremely poor people in Anhui Province accounted for the highest proportion of the total rural population, reaching 1.37\%; Shanghai had the lowest proportion, only $0.08 \%$. Looking at the overall situation, Shanghai has the least pressure on assisting and supporting the poorest people in the city. Beijing, Tianjin, and Zhejiang are relatively small; Anhui, Sichuan, and Chongqing are relatively more stressed.

\section{Establishment of basic model}

\section{MODEL CONSTRUCTION}

Without considering inflation, the main influencing factors of financial expenditures for the assistance and support of the extremely poor people are: the number of assistance and support for the extremely poor people, the standard of assistance and support, the average expenditure level, the per capita disposable income of urban and rural residents, and the per capita consumption level of urban and rural residents. The number of people supported by special hardships is related to the division of the poverty line and the poverty alleviation rate of the 
previous year. Taking the above factors into consideration, a standard model of financial expenditures for assistance and support for the poorest people can be constructed as follows:

$$
\text { Pay }_{t}=\sum_{i=0}^{1} S_{i, t} \text { Average }_{i, t-1}\left(1+C_{i, t}\right)
$$

Pay $_{t}$ represents the financial expenditure for the assistance and support of the extremely poor people in year $t, i=0,1$ represents the urban or rural population when $i$ is taken as 0 or 1 . $S_{i, t}$ represents the number of urban or rural population enjoying assistance and assistance for the extremely poor people in year $t$, Average $e_{i, t-1}$ represents the average level of assistance and support for the urban or rural extremely poor people in the year $t-1$, and $C_{i, t}$ represents the growth rate of per capita consumption expenditure in urban and rural areas.

\section{Establishment of prediction model}

Based on the above influencing factors, when the data is true and some of the influencing factors fluctuate greatly, a time series can be generated based on the assistance and support expenditures of the poor people in the past few years, and then corresponding time series models can be established, such as common ARIMA models, gray GM Model, Holt twoparameter index model, BP model, etc. According to the value of the rescue expenditures of the extremely poor people from 2002 to 2018, after the hypothesis test, it was found that the Holt two-parameter index model has a better fit. Therefore, research can also be carried out by establishing Holt two-parameter index model for simple prediction.

Holt's two-parameter exponential smoothing method is suitable for time series with a linear growth trend. The basic model is as follows:

$$
\begin{gathered}
S_{t}^{(1)}=\alpha y_{t}+(1-\alpha) S_{t-1}^{(1)} \\
S_{t}^{(2)}=\alpha S_{t}^{(1)}+(1-\alpha) S_{t-1}^{(2)} \\
\text { among them, }\left\{\begin{array}{l}
\hat{Y}_{t}=2 S_{t}^{(1)}-S_{t}^{(2)} \\
b_{t}=\frac{a}{1-a}\left(S_{t}^{(1)}-S_{t}^{(2)}\right)
\end{array}\right.
\end{gathered}
$$


Among them, $y_{t}$ represents the actual value of period $t$, which is the observed value of the

Financial expenditure for assistance and support for the extremely poor people in period $t, S_{t}^{(1)}$

$\& S_{t-1}^{(1)} \quad$ represents the primary exponential smoothing value of periods $t$ and $t-1$, and $S_{t}^{(2)}$

$\& S_{t-1}^{(2)}$ represents the second exponential smoothing of period $\mathrm{t}$ and $t-1$ Value. $\alpha$ is the exponential smoothing coefficient, and the value range is $[0,1]$, and $T$ is the number of prediction periods. $\hat{Y}_{t+T}$ is the predicted financial expenditure for assistance and support for the future impoverished people.

Another Holt winter model can also be adopt in this prediction, Holt winter no season model has good prediction performance for the trend series without seasonal factors, which is expressed as follows:

$$
\begin{gathered}
\hat{x}_{t+1}=\alpha x_{t}+(1-\alpha)\left(x_{t-1}+r_{t-1}\right), 0<\alpha<1 \\
\hat{r}_{t}=\beta\left(\hat{x}_{t+1}-\hat{x}_{t}\right)+(1-\beta) r_{t-1}, 0<\beta<1
\end{gathered}
$$

$\alpha, \quad \beta$ are two smoothing coefficients, $\hat{x}_{t+1}$ is the forecasted financial expenditure sequence after smoothing, and $\hat{r}_{t}$ is the trend sequence after smoothing. The initial values of the two series are determined as the following two points: the initial value of the smooth series $\hat{x}_{1}=x_{1}$ and the initial value of the trend series $r_{0}=\frac{x_{n+1}-x_{1}}{n}$, that is, arbitrarily specifying an interval length $n$, and using the average trend of this interval as the initial of the series trend value.

\section{MODEL CALCULATION RESULTS}

According to the financial expenditure value of assistance and support for the extremely poor from 2002 to 2018, the Holt two parameter exponential smoothing model can be used to get the trend graph in Figure 2. According to the image, we can see that the financial expenditure for the assistance and support of the extremely poor has a significant long-term linear trend. According to the output results, the following analysis can be made:

The prediction equation of the financial expenditure for the assistance and support of the extremely poor in Holt-Winters model is as follows:

$$
\begin{gathered}
\hat{x}_{t+1}=0.7915 x_{t}+0.2085\left(x_{t-1}+r_{t-1}\right), 0<\alpha<1 \\
\hat{r}_{t}=\left(\hat{x}_{t+1}-\hat{x}_{t}\right), 0<\beta<1
\end{gathered}
$$




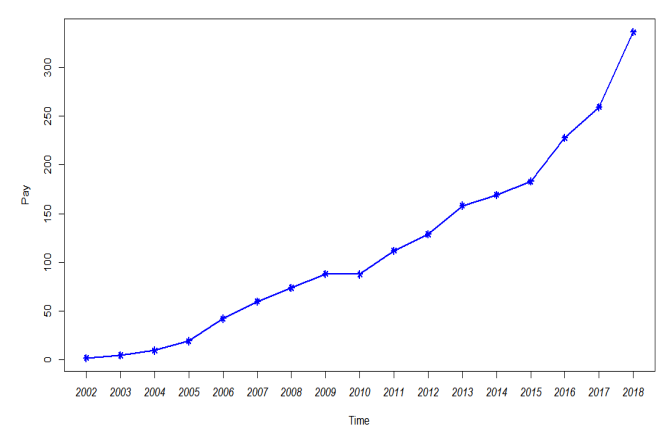

Fig. 2 Financial expenditure trend of assistance and support for the extremely poor in 2002-2018

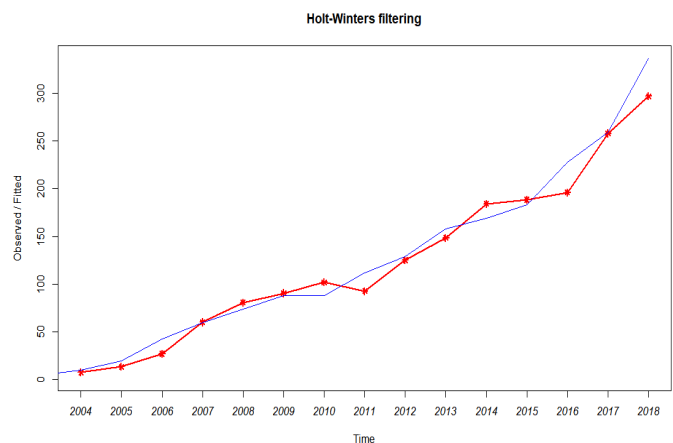

Fig. 3 Fitting effect of Holt-winters parameter exponential smoothing model

According to the model formula, the trend sequence of the model in 2002-2018 can be obtained. According to the fitting between the predicted sequence and the actual value, the fitting effect chart can be obtained, as shown in Figure 3. It can be seen that in the long run, the overall fitting effect of the model fitting value and the actual value is good, the prediction bias is small, and the better prediction data can be obtained. According to the obtained model, forecast the data in the next five years, namely 2019-2023, as shown in the table below.

Table 5 Forecast value of financial expenditure for assistance and support of urban extremely poor people in 2019-2023

\begin{tabular}{cccccc}
\hline Year & $\begin{array}{c}\text { Point } \\
\text { Forecast }\end{array}$ & Lo80 & Hi80 & Lo95 & Hi95 \\
\hline 2019 & 397.3488 & 377.4753 & 417.2222 & 366.9550 & 427.7425 \\
2020 & 466.5103 & 429.2985 & 503.7222 & 409.5997 & 523.4210 \\
2021 & 535.6719 & 475.5744 & 595.7694 & 443.7607 & 627.5831 \\
2022 & 604.8335 & 517.8232 & 691.8437 & 471.7627 & 737.9042 \\
2023 & 673.9950 & 556.7054 & 791.2846 & 494.6161 & 853.3740 \\
\hline
\end{tabular}

Data source: Self sorting of forecast results. 


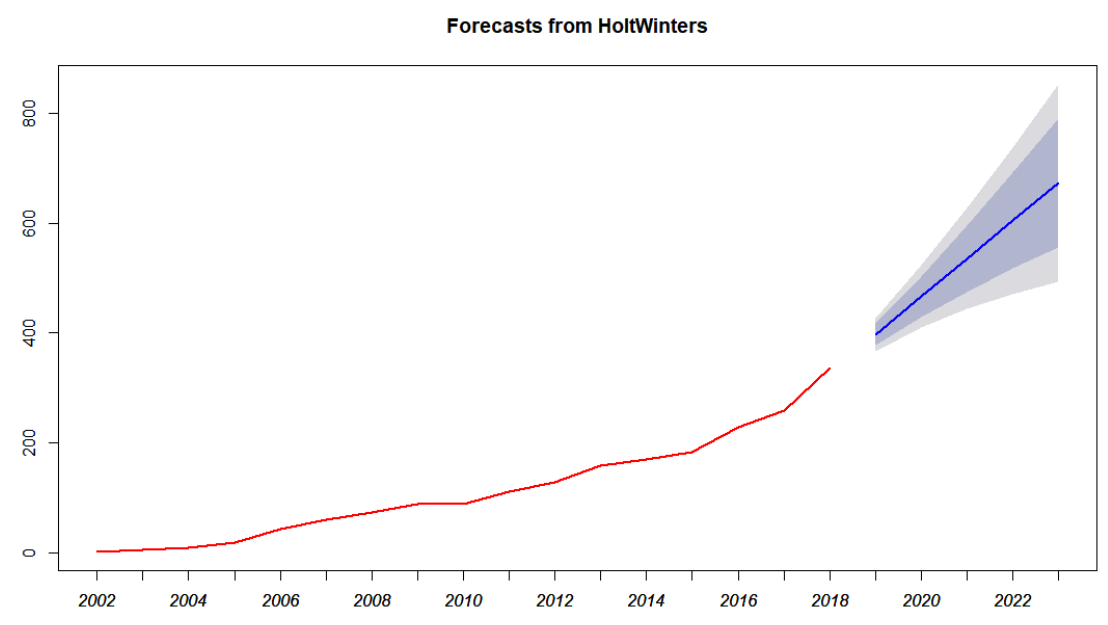

Fig. 4 Prediction of assistance and support expenditure for the extremely poor in 2019-2023

According to the results, with the economic development and the increase of the per capita necessary consumption expenditure, the per capita expenditure of the assistance and support for the extremely poor increased, which led to the continuous increase of the assistance and support expenditure for the extremely poor in recent years. In the next few years, the expenditure for the assistance and support of the extremely poor will maintain a stable upward trend. According to the forecast results, the financial expenditure for the assistance and support of the extremely poor will be 397.3488, 466.5103, 535.6719, 604.8335 and 673.9950 respectively in $2019-2023$, with the annual growth rate of $14.14 \%$ after the first increase.

\section{CONCLUSION}

According to the prediction of the financial expenditures for aid and support for the poor people, it is found that the financial expenditures for aid and support for the poor people in China have a significant long-term trend, but the growth rate of expenditure has increased significantly in recent years. In general, it mainly manifests in the following aspects.

First, after the expenditures for the assistance and support of the extremely poor people in urban and rural areas are separately listed, the scale of assistance and support for the extremely poor people in rural areas has gradually decreased, but the financial expenditure on assistance and support for the extremely poor people has increased significantly. The increasing trend of the rescue scale of urban poor people is basically similar to the increasing trend of fiscal expenditure, and the difference is small. According to the statistics of the Ministry of Civil Affairs, the difference in the standard of assistance and support for the extremely poor people in urban and rural areas nationwide has gradually narrowed, which explains the policy orientation of promoting balanced development in urban and rural areas, and it is gradually reflected in the assistance and support for the extremely poor people. At the same time, according to the calculation formula of the per capita expenditure of assistance and support for the extremely poor people $=$ total financial expenditure $/$ the number of assistance and assistance per capita of the extremely poor people, in 2018 , the average urban and rural extremely poor person can receive an average of 580.8 yuan per person per month; when the urban and rural areas are calculated separately, the average urban poor can receive 887.5 yuan per person per month, the average rural person can enjoy 562.1 yuan per person per month. There is still a certain difference between urban and rural areas, but the difference has reached the lowest compared to 2015-2017. Nationally, some regions have gradually unified urban and 
rural assistance standards, such as Tianjin, and most provinces, districts, and cities still have certain urban-rural differences.

Second, due to differences in economic development levels and regional consumption expenditures, the provinces have significant differences in the standard of assistance and support for urban and rural poor people. For example, the assistance expenditures for the urban poor people calculated in 2017 can reach an average of 2331.58 yuan and 2213.70 yuan per person per month in Qinghai and Beijing respectively; but the data calculated by Sichuan, Shanxi and Gansu provinces average per person per month less than 400 yuan. However, in the national public data, there are no clear policies and regulations that show that the differences in publicity standards in different places are linked to the consumer spending and local price levels. In the case of a large subsidy gap, it may not be possible to guarantee equalization of service levels in various places.

Third, in terms of raising funds for assistance and assistance for the poorest people, the "Interim Measures for Social Assistance" and "The Reform Plan for the Division of Common Financial Authority and Expenditure Responsibilities of Central and Local Governments in the Basic Public Service Field" only stipulated that the assistance and support funds should be provided by counties and cities. The finances make arrangement on their own, and provincial and municipal finances provide certain subsidies through the central government's subsidy for the poor. Income from rural collective operations can also subsidize and improve the lives of those in need. There is no clear regulation on the specific financial responsibilities and funding ratios that governments at all levels need to assume. At the same time, in the distribution of powers, the powers of assistance and support for the poorest people are obviously concentrated downwards. The central government has only one exclusive function, and the other 57 powers are mainly borne by local governments. At present, most countries that have implemented social security laws or fiscal budget laws have established a fiscal responsibility system for social assistance funds shared by governments at all levels, and there is an urgent need to clearly define the proportion of government funds at all levels.

Fourth, the standard setting of assistance and support for the needy needs to be improved. Firstly, in China's social assistance framework system, only urban and rural minimum living standards are publicized on a monthly basis, and the standard of assistance and support for the poorest people is not sufficiently transparent. Under the goal of building a well-off society in China in 2020 to achieve the goal of poverty alleviation for the absolute poor; there is still a certain shortage of standards for the assistance and support of the extremely poor people by using the current absolute poverty standards. The existing standards may not be able to guarantee the basic lives of the extremely poor people. Consider the perspective of expenditure poverty.

\section{Reference}

Lin min gang. General theory of social assistance. Beijing: Science Press, 2017:10

Wang Sibei, et al. "Over 5 Million People Benefit from National Assistance and Support System for Specially Poor People", China Youth Daily, February 18, 2016.

Wang Zhikun. "China Social Assistance Development Report 2013", China Social Publishing House 2015, P60.

Su Zhenyu, Long Yong, Wang Yu.Monthly Load Forecasting Method Based on Seasonal Adjustment and HoltWinters [J] .China Management Science, 2019,27 (03): 30-40.

Li Cangqi, Lu Yan.Analysis of Internet Penetration in China Based on Holt-Winters Filtering Model [J] .Statistics and Decision, 2016 (13): 90-93. 
Zhang Zhanbin, Feng Qiaobin, Huang Yan.Estimation of Fiscal Expenditure and Spatiotemporal Distribution of Urbanization of Rural Migrants in China [J] .Journal of Central University of Finance and Economics, 2013 (10): 17. 